\title{
Sulfur Hexafluoride
}

National Cancer Institute

\section{Source}

National Cancer Institute. Sulfur Hexafluoride. NCI Thesaurus. Code C84187.

A contrast agent composed of an inorg anic fluorinated inert gas comprised of six fluoride atoms bound to one sulfur atom, with potential diagnostic activity upon imaging. Upon inhalation of sulfur hexafluoride (SF6), the gas is distributed throug hout the lungs. Upon subsequent ultrasound imaging, the lung vasculature can be imaged and pulmonary perfusion can be assessed. 